\title{
Türkçe Kaleme Alınmış İlk Basit İlaçlar Kitabı ve Yazarı: Edviye-i Müfrede ve İshak \\ Bin Murad*
}

\author{
The First Simple Drugs Manuscript Written in Turkish and Its Author: Edviye-i Müfrede and İshak Bin \\ Murad \\ Özgür Kıran', Selim Kadığluii \\ 'Dr.Öğr.Üyesi, Ahi Evran Üniversitesi Tıp Fakültesi, Tıp Tarihi ve Etik AD., https://orcid.org/0000-0002-1229-5497 \\ iiProf. Dr., Çukurova Üniversitesi Tıp Fakültesi, Tıp Tarihi ve Etik AD., https://orcid.org/0000-0002-5803-3708
}

öz

Bu makalede Grek-Roma tıbbı olarak başlayıp İslam tıbbı olarak devam eden uzun soluklu geleneğin geç döneminde bitkisel droglarla tedaviyi esas alan bir eser olan İshak bin Murad'ın Edviye-i Müfrede'si ele alınmıştır. Yazarı hakkında günümüze ulaşan fazla bilgi bulunmayan ve içerik yönünden ağırlıklı olarak basit ilaçlar ile onların kullanım endikasyonlarını bildiren bir el kitabı olan bu eser, söz konusu geleneğin zihniyetini anlamayı ve evriminin ulaştığı noktayı ortaya koymayı sağlamaktadır. Edviye-i Müfrede'de el kitabı olmanın doğasına uygun olarak çok sayıda konuya değinilmesi ancak bunların hiçbiri hakkında ayrıntıya girilmemesi söz konusudur. Dört ana bölüm halinde düzenlenmiş olan kitapta çoğu tıbbi bitki niteliğinde 260 basit ilaç yer almaktadır. Kitap kullanım endikasyonlarını da içeren bu basit ilaçlar listesinin yanı sıra farklı özel konuların ele alındığı metinler ve farklı hastalıklara yönelik tedavi ajanlarının tanıtılığı ikinci bir liste de içermektedir. Konunun ele alınışı bağlamında eserin günümüz alfabesine aktarılmış metni üzerinde çalışıımış, onu ve yazarını konu edinen çalışmalardan da yardımcı kaynak olarak destek alınmıştır.

Anahtar Kelimeler: Tıp Tarihi, Bitkisel Illaçlar, Müfred Devalar, İshak bin Murad, İslam Tıbbı

\section{ABSTRACT}

In this paper, an ancient manuscript focused on the therapy with herbal drugs; i̇shak bin Murad's Edviye-i Müfrede which is a product of the long-standing tradition, beginning as Greek-Roman medicine and continuing as Islamic medicine has been evaluated. This manuscript that there is very little information about its author is a handbook regarding predominantly simple drugs and their indications. It is possible to comprehend the mentality and the final situation of the above-mentioned tradition by evaluating this book. As a sample of handbook Edviye-I Müfrede contains many different topics but none of them is processed in detail. The book that has four main chapter contains indication information of 260 simple drug, mostly medicinal plants. There are also articles regarding different medical topics and a list of therapeutic agents of several health problems in the book. In terms of methodology transcription of the original text was examined and some selected works regarding it and its author were used as supporting materials.

Key Words: History of medicine, Herbal drugs, Simple drugs, İshak bin Murad, Islamic medicine

\footnotetext{
*Mersin Üniversitesi Tıp Fakültesi Lokman Hekim Tıp Tarihi ve Folklorik Tıp Dergisi, 2022; 12 (1): 3-17

DOI: $10.31020 /$ mutftd.989269

e-ISSN: 1309-8004, ISSN 1309-761X

Geliş Tarihi-Received: 31 Ağustos 2021; Kabul Tarihi - Accepted: 10 Kasım 2021

Iletişim - Correspondence Author: Özgür Kıran <ozgurkiran@gmail.com>
} 


\section{Giriş}

Bu makale “"De Materia Medica ve Edviye-i Müfrede Işığında Anadolu'da Bitkilerle Tedavi” başlıklı doktora tezinin Türkçe yazılmış, yazıış tarihi bilinen ilk basit ilaçlar kitabı olan Edviye-i Müfrede ve onu kaleme alan İshak bin Murad ile ilgili bölümüne dayanmaktadır. ${ }^{1,2}$ Makalenin dört alt bölümünden ilkinde eser ve yazar hakkında genel bilgi aktarımı yapılmış, ikinci ve üçüncü alt bölümlerde eserin günümüze ulaşan nüshalarına ve kısımlara ayrılma düzenine değinilmiş, dördüncü alt bölümde ise iki tabloya yer verilmiş; ilk tabloda Edviye-i Müfrede'de yer alan tüm droglar liste halinde sunulmuş, ikincide endikasyona göre hangi drogların önerildiği bilgisi aktarılmıştır. Edviye-i Müfrede görece yakın tarihte yayımlanmış ve hakkında çalışmalar da yapılmış bir eser olup bu makalede tıp tarihi açısından bir kez daha ele alınması tanınmasına ve tartışılmasına katkı sağlamaya yöneliktir.

\section{Yazar ve Eser Hakkında}

Illk Türkçe tıp yazmalarının kaleme alınışı XIII.-XIV. yüzyılda Anadolu'da gerçekleşmiştir. Erken örnekler arasında bilinen en eski eser Hekim Bereket'in Tuhfe-i Mübarizi'si, en tanınan ise Hacı Paşa'nın Müntehab-ı Şifa'sıdır., ${ }^{3,4}$ Basit ilaç kitapları özelinde ilk Türkçe eser çevirmeni bilinmeyen Müfredat-ı İbn Baytar Tercümesi; doğrudan Türkçe yazılmış ilk eser ise bu çalışmanın konusu olan Edviye-i Müfrede'dir. ${ }^{5-7}$ Edviye-i Müfrede'nin yazıldığı yıl bilgisini içermesi dikkate değer bir özelliğidir. ${ }^{2}$

Osmanlı tıbbında Türkçe olarak kaleme alınan ve yazılış tarihi bilinen ilk eser olması bakımdan önem taşıyan Edviye-i Müfrede'nin yazarı İshak bin Murad hakkında bilinenler çok az; neredeyse eserin sahibi olmasıyla sınırlıdır. ${ }^{8-15}$ "Hoca Tabib" olarak anıldığı ve Bursa Yıldırım Darüşşifası'nda hasta kabul ettiği ve öğrenci yetiştirdiği şeklinde bilgiler bulunmakla birlikte bunların doğruluğu şüphelidir. ${ }^{10,16}$

Öte yandan kitabın ismi konusunda da bir belirsizlik söz konusudur; kitabın başlangıç kısmında nerede ve ne zaman yazıldığının yanı sıra bir edviye-i müfrede yani müfred devalar, tek etken madde içeren basit ilaçlar derlemesi olduğu belirtilmektedir. ${ }^{17}$ Bu çerçevede başlık halinde gösterilmiş olmayan "Edviye-i Müfrede"nin kitabın özel adı mı yoksa ondan niteliğini belirterek söz etme bağlamında kullanılan bir kalıp mı olduğu tartışmaya açıktır. ${ }^{2,17}$

"Havâssü'l- Edviye" (ilaçların Özellikleri) ve "Hulâsatü't- Tıb" (Tıbbın Özeti) kitaba yakıştırılan diğer adlardır. ${ }^{16}$ Bunların ilki "Edviye-i Müfrede" gibi eserin ilk kısmına gönderme yapmaktadır. ${ }^{16}$ ikinci konusunda Demirhan Erdemir, katıldığını belirterek, Sarton'un bu ismin içeriğin tümünü daha iyi ifade ettiği şeklindeki görüşünü aktarmaktadır. ${ }^{16}$ Kitap kimi kayıtlarda, genellikle birlikte ciltlenmiş olmalarından kaynaklanan bir karışıklıkla, Hacı Paşa'nın kitabının adıyla "Müntehab-ı Şifa” olarak da geçmektedir., 7,17

Adıvar, Osmanlı Türklerinde ilim'de eser hakkında şu bilgileri vermektedir: "Murat I ve Yıldırım Beyazıt devirlerinde (1359-1402) Osmanlı ülkesinde tıp alanında bir hareket görülmeye başlıyor"; "... yazılan ilk tıp eserinin Havass-ül-Edviye adıyla ishak bin Murad adında biri tarafından derlendiğini sanıyoruz"; "Bu kitap 792 (1387) yılında 'Gerede kalesinin katında ve Erkot dağında cem' olunmuştur" (dağın günümüzdeki adı "Arkut"tur); "Eserde birtakım ilaçların etkileri kısaca ve bayağı bir yolla anlatılmaktadır. Bilgilerinin büyük bir kısmının Zeyneddin bin Issmail-ül- Cürcanî’nin eseri olan Zahire-i Harezmşahî'den ve bir de ibn Sina'nın Kanun'undan alınmış olduğu görülür. En çok rastlanan hastalıkların tedavisinden de kısaca bahseden bu yazara dair bildiğimiz bir şey yoktur". 2,7,17

Uludağ, Beş Buçuk Asırlık Türk Tababeti Tarihi kitabında İshak bin Murad'ın kitabının, isminden de anlaşılacağı üzere her şeyden evvel bir "müfredat-ı tıb", her biri kendi başına bir derde deva olan basit ilaçlardan sayılan bitkilerden bahseden bir kitap olduğunu belirtmiştir. ${ }^{12}$ Yine aynı kitapta, Edviye-i Müfrede'de görülen bilgilerin çoğunun derin gözleme ve deneye dayanmadığını ve kitabın yazılışı esnasında Hipokrat'ın ve Galen'in bilgilerinden epeyce faydalanıldığı ifade etmiştir. ${ }^{12}$ 
Ağırakça, Osmanlı Tıbbının Kaynakları başlıklı makalesinde İshak bin Murad'ın II. Murad devri ilim adamlarından, tabip ve mütercim olduğunu ifade etmiştir. ${ }^{18} \mathrm{Hem}$ Ağırakça hem de Demirhan Erdemir, i̇shak Bin Murad'ın İbn-i Cezle'nin genel hastalıklar ve ilaçları aktardığı Takvimü'l-Ebdan fi'ilmi't-Tıb adlı eserini Türkçeleştirdiğini belirtmekte, Ağırakça İbn-i Baytar'ın Baytarneme'sinin Türkçe çevirisinin de ona ait olduğunu dile getirmektedir. ${ }^{16,18}$

Türk tıp tarihi hakkındaki değişik kaynaklarda bu bilgiler tekrarlanmakta; Edviye-i Müfrede'nin yazılış tarihi belli ilk Türkçe tıp kitabı olduğu, basit ilaçlar hakkında temel tıbbi bilgiler içerdiği, derleme niteliği taşıdığı vurgulanmaktadır. ${ }^{8-14}$ İshak bin Murad hakkında yazılanlar ise büyük ölçüde eserinden yola çıkılarak yapılan yorumlardır. ${ }^{8-14} \mathrm{Bu}$ yorumlar bağlamında yazara en olumlu yaklaşanların Uludağ ve Bayat olduğunu söylemek olanaklıdır. ${ }^{8-14}$

Edviye-i Müfrede dilinin ağır olmamasının yanı sıra ele aldığı konuları derinlemesine işlememesi, onların anlaşıması için ön bilgi gerektirmemesi bakımından hem hekimlere gündelik uygulamalarıyla ilgili hatırlatmalar yapan hem de tıp dışı okuryazar kişilere kimi temel bilgileri aktaran bir el kitabı olarak değerlendirilebilir. Eser İslam Tıbbı çerçevesinde incelendiğinde, İshak bin Murad'ın kendinden önce gelen yazarlardan özellikle İbn-i Sina'dan etkilendiği ve yararlandığı; humoral patoloji teorisini benimsemiş ve eserini bu teoriyi esas alarak hazırlamış olduğu görülmektedir. İshak bin Murad, farklı sağılık sorunlarına karşı etkili olan çok sayıda bitkiden söz ederken, bunlar hakkında fiziksel özellikleri, yetiştikleri yerler gibi genel bilgiler aktarmamakta; basit bir dille humoral özelliklerini ve tıbbi kullanımlarını anlatmakla yetinmektedir.

Edviye-i Müfrede'nin ana kaynağının İbn-i Sina'nın el-Kanun fi't-Tıb adlı eserinin basit bitkisel drogların tanıtılığı ikinci kitabı olduğunu söylemek olanaklıdır. İshak bin Murad bu kaynaktan yararlanma bağlamında temel bilgiyi değil uygulamayı esas alan ve ona dair içeriği seçerek kendi eserine aktaran bir yaklaşım benimsemiştir. Bu durumu bir dizi örnek üzerinden ortaya koymak yerinde olacaktır.

İbn-i Sina eserinin ikinci kitabında süsenin (Iris florentina L.) genel niteliklerini aktarırken Dioskorides'in kitabından alıntı yapmış, humoral özellikleri olan sıcaklık ve kuruluğu ekledikten sonra dalak ağrısı için kullanıldığını belirtmiştir. ${ }^{19}$ i̇shak bin Murad ise Edviye-i Müfrede'nin birinci kısmındaki süsen maddesinde sadece bu bitkinin sıcak ve kuru olduğunu ve dalak ağrıları için kullanıldığını bildirmiştir. ${ }^{2}$

İbn-i Sina Mekke pelesenki (Commiphora opobalsamum L.) hakkında bilgi verirken, Dioskorides'in bu ağacın sadece İsrail ve Filistin'de bulunduğunu ve boylarının birbirinden farklı olduğunu söylediğini ifade etmiş; bu bilgileri kitabına aktarmayan İshak bin Murad ise bu bitkinin sıcak ve kuru olduğu, baş dönmesine iyi geldiği, idrar yolunu açtığı, yağının soğuk hastalıklarda kullanıldığı bilgilerini sıralamakla yetinmiştir. ${ }^{2,19}$

İbn-i Sina tarçının (Cinnamomum sp.) genel özelliklerini aktarırken Dioskorides'in ifadelerinden faydalanmış ve etkilerini açıklarken Dioskorides'in bütün tarçınların etkisinin açıcı, ısıtıcı ve düzeltici olduğunu, tüm kötü etkileri çekip iyileştirdiğini söylediğini belirtmiştir. ${ }^{2,19}$ Ardından, Edviye-i Müfrede'de de yer alan, tarçının sıcak ve kuru olduğu, göze çekilirse iyi geldiği, beyni rahatlattığı, kronik nezleyi giderdiği, mideyi güçlendirdiği ve haşere sokmalarında kullanıldığı bilgilerine yer vermiştir. ${ }^{2,19}$

\section{Edviye-i Müfrede Nüshaları}

Edviye-i Müfrede'nin günümüze ulaşan ve bilinen altı yazma nüshasından dördü Türkiye'de ikisi Fransa'da ve Almanya'da farkı kütüphanelerinde muhafaza edilmektedir. Bunlar hakkında kısa bilgi notları istinsah edilme tarih sırasına göre aşağıda yer almaktadır. Eldeki nüshalardan hareketle eserin genellikle XIV. yüzyılda yaşamış tıp alimi Hacı Paşa’nın Müntahab-ı Şifa adlı kitabıyla ile birlikte istinsah edildiği; ikisinin tek bir kitap gibi kullanıldığı saptamasını yapmak olanaklıdır. ${ }^{2,7,17}$ 


\section{Paris Nüshası (Bibliotheque Nationale A.F. 170)}

Eser Müntahab-ı Şifa ile birlikte bulunmakta; 260 varak tutan yazmanın 1a-188a sayfaları arasında Müntahab-ı Şifa, 188b'den itibaren de Edviye-i Müfrede yer almaktadır., ${ }^{2,7,17}$ istinsah tarihi 16 Zi'l-ka'de 900 (8 Ağustos 1495) olarak belirtilmiştir. Harekeli nesihle yazılmış olan bu nüsha, eldeki yazmalar içerisinde en tutarlısı olarak değerlendirilmektedir. ${ }^{2,7,17}$

2. Malatya Nüshası (Malatya Genel Kütüphanesi 1196-1)

Yazmanın ilk 77 varakında Edviye-i Müfrede, daha sonraki 188 varakında Müntahab-ı Şifa yer almaktadır. ${ }^{2,7,17}$ Her iki eser de Muhammed el-Zenceri tarafından hicri 954 (1547) yılında istinsah edilmiştir. ${ }^{2,7,17}$ Harekeli nesih ile yazılmıştır. Kitap ismi metin dışında yer almakta ve sonradan yazıldığı anlaşılmakta olup Kitab-ı Müntahab-ı Şifa ve Kütübün Ahar min Mu'teberani't-Tıb biçimindedir. ${ }^{27,17}$

\section{Bursa Nüshası (Haraççıoğlu Kitaplığı No. 1134)}

Nüshada Edviye-i Müfrede ve Müntahab-ı Şifa birlikte bulunmaktadır. Edviye-i Müfrede ilk elli beş varak içerisindedir. ${ }^{2,7,17}$ Sonraki yüz otuz altı varakta Müntahab-ı şifa yer almaktadır. İstinsah edildiği yıl hicri 1083'tür (1672). Kütüphane kayıtlarında her iki eser Müntahab-ı Şifa adı altında yer almakta ve yazarı İshak Bin Murad olarak gösterilmektedir., 2,7,17

\section{Topkapı Nüshası (Topkapı Kitaplığı, Revan Kısmı No. 1693)}

Takvimü'l-Büldan adlı eserin arkasına eklenmiş eksik bir nüshadır. ${ }^{2}$ Edviye-i Müfrede'nin en baştan 'kavun' maddesine kadar olan kısmı nüshanın 85b-112a sayfaları arasında yer almaktadır. Edviye-i Müfrede kitaplık kayıtlarına geçmemiştir. ${ }^{2,7,17}$ Yazı ve kağıt karakterlerinden XIX. yüzyılda istinsah edildiği anlaşılmaktadır. ${ }^{2,7,17}$ Bu eksik nüshada eserin dilinin oldukça değiştirildiği, birtakım kelimelerin yerine Arapça karşılıklarının kullanıldığı ve ayrıca metninde eklemeler ve çıkarmalar şeklinde birçok değişiklik yapılmış olduğu görülmektedir. ${ }^{2,7,17}$

\section{Ali Emiri Nüshası (Millet Kütüphanesi Tıp Yazmaları No. 109)}

XIX. yüzyılda güzel bir harekesiz rik'a ile yazılmış olan ve 77 varak tutan bu nüshanın her sayfasında on yedi satır bulunmaktadır. ${ }^{2,7,17}$ Adı kütüphane kayıtlarına "Kitab-ı Edviye-i Müfrede" olarak geçmiştir. ${ }^{2,7,17}$ Eserin Adnan Adıvar tarafından incelenen nüshası budur., ${ }^{2,717}$ Yeni olmasına karşın Paris ve Malatya nüshaları ile çok uyumlu ve onlardaki kimi yanlışların düzeltilmesine yardımcı olan bir nüshadır. ${ }^{2,7,17}$

\section{Gotha Nüshası}

Önler'in ve Canpolat'ın çalışmalarında kütüphane kaydı aktarılmayıp Pertsch katalogunda tanıtıldığı ifade edilen bu nüshanın adı "Müntahab-ı Şifa" olarak verilmektedir., ${ }^{2,17}$ Ancak ilk ve son sayfaları sonradan eklenen notlarla dolu olduğu bildirilen bu nüshada, eser adının metin içinde mi geçtiği yoksa bu notlar arasında mı bulunduğu belirtilmemektedir. ${ }^{2,7,17}$ Eserin genellikle Müntahab-ı Şifa ile birlikte bulunmasından hareketle bu nüshanın ikili bir yapıdan ayrılmış ve ayrılma sonrası diğer parçanın ismini muhafaza etmiş olduğunu düşünmek olanaklıdır. ${ }^{2,7,17}$ Bu nüshada eserin yazılış yııının diğerlerinden farklı verilmiş; iki yıl öne çekilerek hicri 790 (1388) olarak gösterilmiş olması dikkat çekicidir. ${ }^{2,7,17}$

Bu makalenin dayandığı tez çalışmasında Mustafa Canbolat ve Zafer Önler tarafından yayına hazırlanan, Paris nüshasının esas alındığı, eserin tıpkıbasımın yanı sıra transkribe edilmiş tam metnini de içeren Türk Dil Kurumu yayını Edviye-i Müfrede'den yararlanılmıştır. ${ }^{2}$ Bu kitap eserde yer alıp halen kullanılmayan sözcüklerin günümüz dilindeki karşııılarının yer aldığı bir sözlük de içermektedir. ${ }^{2}$ Mustafa Argunşah "Edviye-i Müfrede'nin neşri üzerine düşünceler" adlı makalesinde, kitabın Türkoloji çalışmaları açısından kapsamlı bir eleştirisini yapmıştır. ${ }^{20}$ 


\section{Edviye-i Müfrede'nin Kısımları}

Edviye-i Müfrede dört kısımdan oluşmaktadır. Illk kısımda alfabetik düzende sıralanmış drogların kullanım alanları, ikinci kısımda belirli endikasyonlar için kullanılan droglar, üçüncü kısımda farklı yazarların eserlerinden yapılan alıntılar, çeşitli ilaç terkipleri ve cinsel konulara ilişkin bilgiler ve dördüncü kısımda Arapça, Farsça ve Türkçe terimler sözlüğü yer almaktadır.

I. Kısım (Paris nüshası, 1b-43b):

Bu kısımda tek başına ilaç olarak kullanılan bitkisel, hayvansal ve madensel droglar, büyük ölçüde alfabetik bir düzen içinde sıralanmış ve her birinin özellikleri ile başlıca hangi hastalıklara karşı kullanılacakları, zararları, zararlarının nasıl giderileceği konularında bilgiler verilmiştir. ${ }^{2,7,17}$ Kısmın son bölümü farklı bir yaklaşımla yazılmış; sağlık sorunları esas alınarak bunların her birine hangi maddelerin iyi geldiği özet halinde anlatılmıştır. ${ }^{2,7,17}$

Birinci kısmın ılık sudan söz edilen bölümünde bu genel şablonun dışında kalan hoş bir anekdot bulunmaktadır. Bu anekdotta “isa zamanında” bir kişinin ölüyü dirilttiğini haber alan Galen'in “Gidin bakın, eğer ılık su ile diriltmişse hikmet bilir bir hekimdir, eğer ılık su ile değilse mucizesi olan bir peygamberdir, ona uyun" şeklindeki yorumu aktarılmaktadır. ${ }^{2}$

II. Kısım (Paris nüshası, 43b-57a):

Hastalıklar ve tedavilere ilişkin olan bu kısım, makale olarak adlandırılan dört alt bölüme ayrılmıştır. Başla ilgili hastalılardan başlayarak, boyun, göğüs, karın bölgesi ve ayaklara ilişkin hastalıklar yukarıdan aşağıya ilerleyen bir sıralamaya göre ele alınarak nedenleri, özellikleri ve sağaltımları konusunda bilgiler verilmiştir. ${ }^{2,7,17}$ Kısmın sonunda nabızla ilgili bilgi aktaran ve kitaba sonradan eklenmiş izlenimi veren kısa bir metin yer almaktadır. ${ }^{2,7,17}$

İlk makalede başla ilgili hastalıklar; baş ağrısı, menenjit, uykusuzluk, çok uyumak, sekte, spazm ele alınmaktadır. 2,7,17 ikinci makalenin konusu insanın yukarı yarısındaki hastalıklar; nezle, kulak çınlaması, dil ağrısı, boğaz ağrısı, akciğer hastalığı, verem, göğüs kafesinde kitle, nefes darlığı, kalp çarpıntısı, ağızdan kan gelmesi, bayılma, bağırsak sancısı, hıçkırık, göbek sancısı, dizanteri, bağırsaktaki gaz sancısı, karaciğer ağrısı, siroz ve sarılıktır. ${ }^{2,7,17}$ Üçüncü makalede insanın aşağı yarısındaki hastalıklar; böbrek ağrısı, mesane hastalıkları, makat hastalıkları, mesaneden idrar ve meninin durmadan aktığı hastalık, fıtık, regı kanının fazlaca akması ve cinsel isteksizlik, eklem sorunları anlatılmaktadır. ${ }^{2,7,17}$ Ağılıklı olarak ciltte olan hastalıklar hakkındaki dördüncü makalede yer alan sağlık sorunları ise, kellik ve cüzam, sam lekesi, çiçek hastalığı, cilt kanseri ve çıbanlar ile ciltle dolaylı ilişkisi bulunan sıtmalar ve nabızlardır., ${ }^{27,17}$

III. Kısım (Paris nüshası, 57a-68a):

Eklektik bir yapısı olan bu kısımda sırayla Cürcani'nin Zahire-i Harzemşahi'sinden ve ỉbn-i Sina'nın Kanun'undan yapılan alıntılar, çeşitli ilaç terkipleri ve cinsel konulara ilişkin bilgiler yer almaktadır. ${ }^{2,7,17}$

Zahire-i Harzemşahi'den alıntılanan bölüm yaşlıların mizaçları ve almaları gereken tedbirler hakkındadır., ${ }^{2,7,17}$ Kanun'dan alıntılanan Arapça ve Farsça karışımı Türkçe çevirisi yapılmamış bölümde İbn-i Sina'nın yemekle ilgili öğütleri ve humoral patoloji teorisi üzerine Galen'in adının geçtiği kısa bir metin bulunmaktadır. 2,7,17

Kısmın bahname izlenimi veren son bölümü yedi alt bölüm halinde olup bunlarda sırayla cinsel ilişkinin yararları, cinsel ilişkinin yararlı olacağı zamanlar, cinsel ilişkinin zararlı olduğu durumlar, cinsel ilişkiden kesilme, cinsel isteği arttırıcı basit maddeler, cinsel isteği arttırıcı karışımlar, cinsel isteğin az olmasının belirtileri işlenmiştir. ${ }^{2,7,17}$ Benzer eserlerde de sıklıkla rastlanan bu konular anlatılırken bir yerde Galen'den 
"abartılı yapılmadığı sürece seksin vücuda çok faydalı olduğu" şeklinde bir aktarım yapılmış, bir başka yerde Hipokrat'ın ismi anılmıştır. ${ }^{2,7,17}$

IV. Kısım (Paris nüshası, 68a-71a):

Arapça, Farsça ve Türkçe terimler sözlüğüdür. Toplam iki yüz kırk dokuz terimin yer aldığı bu sözlük dört kısımdan oluşmaktadır. Hastalık adlarının yer aldığı ilk kısımda 78; organ adlarının ve fizyoloji ile ilgili terimlerin bulunduğu ikincide 80 madde yer almaktadır. Üçüncü kısımdaki 67 madde sebze, meyve, çeşitli bitki ve yiyecek; dördüncüdeki 24 madde ise eşya ve alet adlarıdır., ${ }^{27,17}$ Önceki kısımlarda söz edilmiş olan kimi hastalıkların ve drogların sözlükte yer almaması dikkat çekicidir.

\section{Edviye-i Müfrede'de Yer Alan Droglar}

Edviye-i Müfrede'nin ilk kısmında yer alan müfred devalar hakkındaki bilgiler, maddeler halinde sıralanmış olarak değil bütünlük-süreklilik arz eden bir metnin içine yerleştirilmiş durumda bulunmaktadır. Numaralandırılmış olmaları da söz konusu değildir. Drogların sıralanma düzeninin ne şekilde belirlendiği açık olmayıp kitap kısa bir girizgahı takiben önce üç bitkisel drog örneğinden sonra kategorik bir yaklaşımla etlerden ve ekmeklerden söz edilmesiyle başlamaktadır. Ekmeklerden sonraki sıralanış düzenli halde olup droglar adlarının ilk harflerine göre oluşturulmuş bablara yerleştirilmiş bulunmaktadır.

Kitapta hakkında bilgi verilen drog veya gıda maddesi niteliğindeki müfred devaların toplam sayısı 260 olup bunların 202'si bitkiler, bitki kısımları ve bitki türevi ürünlerdir. "Yağ"ın tıbbi niteliklerinden söz edilen kısımda kökeninin bitki mi, hayvan mı olduğu belirtilmemiştir. Hayvansal ürünlerin sayısı 42 ve inorganik maddelerinki ise 15 'dir. Bu müfred devaların her biri hakkında bilgi aktarımının ardından kitabın ilk kısmının sonunda hastalık veya yakınma niteliğinde 57 farklı sorun sıralanmış ve bunların her birinde hangi drogların kullanılacağı belirtilmiştir.

Tablo 1'de kitaptaki müfred devaların tümünün isimleri metinde söz edilme sırasına göre numaralanarak liste haline getirilmiştir. Bu liste tablonun ilk iki sütununa yerleştirilmiştir. Üçüncü sütunda Edviye-i Müfrede'de kullanılan isimlerin günümüz dilindeki; dördüncüde ise isimlendirme karışıklıklarını önleme adına sadece bitkisel olanların botanik terminolojisindeki karşılıkları yer almaktadır. Hayvan ve inorganik madde isimleri bağlamında karışıklık olasılığı bulunmadığından zooloji ve kimya terminolojilerinden destek alınmamıştır.

Tablonun hazırlanmasında Turhan Baytop’un "Türkiye'de Bitkilerle Tedavi”, "Türkçe Bitki Adları Sözlüğü” ve "Türkiye'nin Tıbbi ve Zehirli Bitkileri”, Ertan Tuzlacı'nın "Türkiye Bitkileri Sözlüğü" ve "Şifa Niyetine: Türkiye'nin Bitkisel Halk İlaçları" adlı kitaplarından, Zafer Önler'in XIV. ve XV. Yüzyıl Anadolu Türkçesi Botanik Terimleri, XIV-XV. Yüzyıl Tıp Metinlerinde Türkçe Bitki Adları adlı makalelerinden ve yayına hazırladığı kitabın sonunda verilen Türkçe sözlükten faydalanılmıştır. ${ }^{11,21-26}$

Tablo 1. Edviye-i Müfrede'de Yer Alan Müfred Devalar.

\begin{tabular}{llll}
\hline & Edviye-i Müfrede'deki Ad & Günümüz Türkçesindeki Ad & $\begin{array}{l}\text { Botanik Terminolojisindeki } \\
\text { Latince Ad }\end{array}$ \\
\hline 1 & Ebem gömeci & Ebegümeci & Malva silvestris L. \\
2 & Dilkü üzümi & Köpek üzümü,Itt üzümü nigrum L. \\
3 & İt boncugi & İt boncuğu & \\
\hline ETLER & & At eti & \\
\hline 4 & At eti & Oğlak \\
5 & Oğlak & Balık eti \\
6 & Balık eti & Yılan balığı \\
7 & Yılan balık & \\
9 & Tarınc balık & Horoz \\
\hline
\end{tabular}




\begin{tabular}{|c|c|c|c|}
\hline 10 & Tavuk & Tavuk & \\
\hline 11 & Serçe & Serçe & \\
\hline 12 & Dilkü eti & Tilki & \\
\hline 13 & Sırtlan eti & Sırtlan eti & \\
\hline 14 & Ayu & Ayı & \\
\hline 15 & Çil eti & Dağ tavuğu & \\
\hline 16 & Sığır eti & Sığır eti & \\
\hline 17 & Oğlak eti & Oğlak eti & \\
\hline 18 & Koyun eti & Koyun eti & \\
\hline 19 & Keçi eti & Keçi eti & \\
\hline 20 & Deve eti & Deve eti & \\
\hline 21 & Gögercin eti & Güvercin eti & \\
\hline 22 & Geyik eti & Geyik eti & \\
\hline 23 & Etmek & Ekmek & \\
\hline 24 & Bazlamac & Bazlama & \\
\hline 25 & Beksimat & Peksimet & \\
\hline 26 & Arpa etmegi & Arpa ekmeği & \\
\hline 27 & Birinç etmegi & Pirinç ekmeği & \\
\hline 28 & Taru etmegi & Mısır ekmeği & \\
\hline 29 & Uruz otı & Sinirli ot & Plantago major L. \\
\hline 30 & Arpa & Arpa & Hordeum vulgare $L$. \\
\hline 31 & Erük & Erik & Prunus domestica $L$. \\
\hline 32 & Emrud & Armut & Pyrus communis $L$. \\
\hline 33 & Yüzerlik & Üzerlik & Peganum harmala $L$. \\
\hline 34 & Üzüm & Üzüm & Vitis vinifera $L$. \\
\hline 35 & Isfinah & Ispanak & Spinacia oleracea L. \\
\hline 36 & Isırgan dikeni & Isırgan & Urtica dioica L. \\
\hline 37 & Eşek Turpi & Eşek turpu & Armoracia rusticana $L$. \\
\hline 38 & Uşnan & Çöven & Saponaria officinalis L. \\
\hline 39 & Ağaç kavunı & Ağaç kavunu & Citrus medica $L$. \\
\hline 40 & Oglan aşı & Çakşır otu & Ferula elaeochytris $L$. \\
\hline 41 & Ağu ağacı & Zakkum & Nerium oleander $L$. \\
\hline 42 & Eftimun & Bağboğan, küsküt & Cuscuta epithymum L. \\
\hline 43 & Efyun & Afyon, haşhaş & Papaver somniferum L. \\
\hline 44 & Egir & Eğir otu, kasıkotu & Acorus calamus $L$. \\
\hline 45 & Egren & Kızılcık & Cornus mas $L$. \\
\hline 46 & Aluc & Alıç & Cratageus monogyna $L$. \\
\hline 47 & Ilgun & Ilgın & Tamarix parviflora $L$. \\
\hline 48 & Alma & Elma & Malus domestica L. \\
\hline 49 & Yılan boncugı & Yılan yastığı & Arum maculatum $L$. \\
\hline 50 & İgde & İğde & Elaeagnus sp. \\
\hline 51 & İklil-ül melik & Sarıyonca, kokulu yonca & Melilotus officinalis L. \\
\hline 52 & Encir & İncir & Ficus carica L. \\
\hline 53 & Anisun & Anason & Pimpinella anisum $L$. \\
\hline 54 & Ayıt & Hayıt & Vitex agnus-castus L. \\
\hline
\end{tabular}




\begin{tabular}{|c|c|c|c|}
\hline 55 & Ayran & Ayran & \\
\hline 56 & Ayva & Ayva & Cydonia oblonga $L$. \\
\hline \multicolumn{4}{|c|}{ BE BABI } \\
\hline 57 & Babadya & Papatya & Matricaria chamomilla L. \\
\hline 58 & Badam & Badem & Amygdalus communis $L$. \\
\hline 59 & Badincan & Patlıcan & Solanum melongena $L$. \\
\hline 60 & Bal & Bal & Mel \\
\hline 61 & Badrık & Yabani fesleğen & Ocimum sp. \\
\hline 62 & Burçak & Burçak & Coronilla coronata \\
\hline 63 & Birinç & Pirinç & Oryza sativa $L$. \\
\hline 64 & Biryan & Büryan kebabı & \\
\hline 65 & Besbase & Küçük hindistan cevizi çek. Kb & Myristica fragrans $L$. \\
\hline 66 & Besfayiç & Bespaye & Polypodium vulgare L. \\
\hline 67 & Buğday & Buğday & Triticum sp. \\
\hline 68 & Bakam & Bakam ağacı, boya ağacı & Caesalpinia echinata $L$. \\
\hline 69 & Beg börki (şehtere) & Şahtere, kadife çiçeği & Fumaria officinalis $L$. \\
\hline 70 & Bögrülce & Börülce & Vigna sinensis $L$. \\
\hline 71 & Bögürtlen & Böğürtlen & Rubus caesius $L$. \\
\hline 72 & Beladır & Beladır ağacı & Semercarpus anacardium $L$. \\
\hline 73 & Belad-ı kimnun & Karaman kimyonu & Carum carvi $L$. \\
\hline 74 & Baldırı kara & Baldırıkara & Adianthum capillus-veneris \\
\hline 75 & Belesan & Pelesenk ağacı, Mekke balsamı & Commiphora opobalsamum \\
\hline 76 & Benefşe & Menekşe & Viola sp. \\
\hline 77 & Peynir & & \\
\hline 78 & Bure & Boraks & \\
\hline 79 & Bure-i ermeni & Kilermeni, Sodyum karbonat & \\
\hline 80 & Boy & Çemen otu & Trigonella foenum graecum \\
\hline \multicolumn{4}{|c|}{ TE BABI } \\
\hline 81 & Tebaşir & Bambu şekeri & Galactites \\
\hline 82 & Tohmekan & Semiz otu & Portulaca oleracea $L$. \\
\hline 83 & Turb & Turp & Raphanus sativus $L$. \\
\hline 84 & Tarhun & Tarhun otu & Artemisia dracunculus $L$. \\
\hline 85 & Teke sakalı & Teke sakalı & Tragopogon porrifolius \\
\hline 86 & Temirhindi & Demirhindi & Tamarindus indica $L$. \\
\hline 87 & Tut & Dut & Morus sp. \\
\hline 88 & Tutiya & Çinkolu bileşik & \\
\hline \multicolumn{4}{|c|}{ SE BABI } \\
\hline 89 & Şirmun & Ilıca, Kaynamış su & \\
\hline \multicolumn{4}{|c|}{ çiM BABI } \\
\hline 90 & Çörek otı & Çörek otu & Nigella sativa $L$. \\
\hline 91 & Çogan & Çöven otu & Gypsophia struthium L. \\
\hline 92 & Çakır dikeni & Çakır dikeni & Eringium campestre \\
\hline 93 & Çigdem & Çiğdem & Colchicum sp. L. \\
\hline 94 & Çügündür & Şeker pancarı & Beta vulgaris-folliora \\
\hline 95 & Çenar & Çınar & Platanus orientalis $L$. \\
\hline 96 & Cevz-i buva & Küçük hindistan cevizi & Myristica fragrans $L$. \\
\hline
\end{tabular}




\begin{tabular}{|c|c|c|c|}
\hline \multicolumn{4}{|c|}{ HA BABI } \\
\hline 97 & Hınna & Kına & Lawsonia inermis $L$. \\
\hline 98 & Hardal & Hardal & Brassica nigra $L$. \\
\hline 99 & Hurma & Hurma & Phoenix dactylifera \\
\hline 100 & Haşhaş & Haşhaş & Papaver somniferum $L$. \\
\hline 101 & Hatmi & Gülhatmi & Althea officinalis $L$. \\
\hline 102 & Hıyarşenber & Acur & Cucumis flexuosus \\
\hline 103 & Hiyar & Salatalık & Cucumis sativus $L$. \\
\hline \multicolumn{4}{|c|}{ DAL BABI } \\
\hline 104 & Dar-ı fulful & Başbiberi & Piper longum \\
\hline 105 & Darçini & Tarçın & Cinnamomum sp. L. \\
\hline 106 & Dopalak & Topalak & Cyperus rotundus $L$. \\
\hline 107 & Durak otı & Dere otu & Anethum graveolens $L$. \\
\hline 108 & Destenbuy & Şamama & Cucumis dudaim \\
\hline 109 & Deniz köpügi & Lüle taşı, eskişehir taşı & Spuma salis \\
\hline 110 & Dilkü taşagı & İtkasarı, tilkitaşağı & Orchis hircina \\
\hline 111 & Demür dikeni & Demirdikeni & Tribulus terrestris $L$. \\
\hline 112 & Duz & Tuz & \\
\hline \multicolumn{4}{|c|}{ ZEL BABI } \\
\hline 113 & Zefni & Defne & Laurus nobilis L. \\
\hline \multicolumn{4}{|c|}{ RA BABI } \\
\hline 114 & Razyane & Rezene & Foeniculum vulgare $L$. \\
\hline 115 & Rasuht taşı & Rastık taşı, antimon & \\
\hline 116 & Rişte & Erişte, ev makarnası & \\
\hline \multicolumn{4}{|c|}{ ZE BABI } \\
\hline 117 & Zac & Demir sülfat & \\
\hline 118 & Zerdalü & Zerdali & Armeniaca vulgaris \\
\hline 119 & Zernih & Zırnık, zerne, amonyum sülfür & \\
\hline 120 & Za'firan & Safran & Crocus sativus $L$. \\
\hline 121 & Zift & Zift & \\
\hline 122 & Zencebil & Zencefil & Zingiber officinalis \\
\hline 123 & Zeyt & Zeytin yağı & Oleum olivae \\
\hline 124 & Zeytun & Zeytin & Olea europea L. \\
\hline \multicolumn{4}{|c|}{ SIN BABI } \\
\hline & SÜDLER & SÜTLER & \\
\hline 125 & At südi & At sütü & \\
\hline 126 & Eşek südi & Eşek sütü & \\
\hline 127 & Deve südi & Deve sütü & \\
\hline 128 & Sığır südi & Sığır sütü & \\
\hline 129 & Avrat südi & Kadın sütü & \\
\hline 130 & Koyun südi & Koyun sütü & \\
\hline 131 & Keçi südi & Keçi sütü & \\
\hline 132 & Süd çürügi & Bozuk süt & \\
\hline 133 & Südlügen & Sütleğen & Euphorbia sp. L. \\
\hline 134 & Süci & Şarap & \\
\hline 135 & Sirke & Sirke & \\
\hline
\end{tabular}




\begin{tabular}{|c|c|c|c|}
\hline 136 & Sarmısak & Sarmısak & Allium sativum L. \\
\hline 137 & Sarmaşuk & Sarmaşık & Hedera helix $L$. \\
\hline 138 & Sufal & Sifal, saksı & \\
\hline 139 & Sakız & Sakız & Pistacia lentiscus L. \\
\hline 140 & Söğüt & Söğüt & Salix sp. L. \\
\hline 141 & Sinirlüce ot & Sinirli ot & Plantago sp. L. \\
\hline 142 & Söğülme & Kebap & \\
\hline 143 & Sumak & Sumak & Rhus coriaria L. \\
\hline 144 & Su kerdemesi & Su teresi & Nasturtium officinale $L$. \\
\hline 145 & Susen & Süsen & Iris sp. L. \\
\hline 146 & Simsim & Susam & Sesamum indicum $L$. \\
\hline \multicolumn{4}{|c|}{ ŞIN BABI } \\
\hline 147 & Şam sakızı & Çam sakızı & Pinus sp. L. \\
\hline 148 & Şeftalu & Şeftali & Prunus persica L. \\
\hline 149 & Şakakul & Yabani havuç, karakök & Pastinaca sativa $L$. \\
\hline 150 & Şeker & Şeker & \\
\hline 151 & Şalgam & Şalgam & Brassica rapa L. \\
\hline 152 & Şınhıyar & Acur & Cucumis anguria $L$. \\
\hline 153 & Şirugan & Şırlağan otu & \\
\hline \multicolumn{4}{|c|}{ SAD BABI } \\
\hline 154 & Sabun & Sabun otu & \\
\hline 155 & Şabr & Sabır otu, sabırlık & Agave americana \\
\hline 156 & Sadef & Sedef otu & Ruta graveolens \\
\hline 157 & Saru boya & Sarıboya otu & Serratula tinctoria \\
\hline 158 & Sığır dili & Sığırdili otu & Anchusa sp. \\
\hline 159 & Sığı kuyruğu & Sığırkuyruğu & Verbascum sp. \\
\hline 160 & Sandal & Sandal ağacı, koca yemiş & Arbutus unedo \\
\hline \multicolumn{4}{|c|}{ DAD BABI } \\
\hline 161 & Zaymuran & Yabani fesleğen & Ocimum basilicum \\
\hline \multicolumn{4}{|c|}{ TI BABI } \\
\hline 162 & Taru & Darı & Panicum miliaceum \\
\hline 163 & Tırfıl & Üçgül & Trifolium campestre \\
\hline 164 & Tataranbu & Oğulotu & Melissa officinalis \\
\hline 165 & Tomalan & Keme, domalan & Terfezia sp. \\
\hline \multicolumn{4}{|c|}{ ZI BABI } \\
\hline 166 & Zayyan & Yasemin & Jasminum officinale \\
\hline \multicolumn{4}{|c|}{ AYIN BABI } \\
\hline 167 & Akırkarha & Pireotu & Anayciclus pytethrum \\
\hline 168 & Aşfur & Yalancı safran, aspir & Carthamus tinctorius \\
\hline 169 & Anber & Amber çiçeği & Geum urbanum \\
\hline 170 & Üd & Öd ağacı & Aquilara aggalocha \\
\hline \multicolumn{4}{|c|}{ GAYIN BABI } \\
\hline 171 & Garikun & Katran köpüğü mantarı & Agaricus campestris \\
\hline \multicolumn{4}{|c|}{ FE BABI } \\
\hline 172 & Ferfiyun & Sütleğen & Euphorbia officinarum $L$. \\
\hline 173 & Fistuk & Fistık & Pistacia vera \\
\hline
\end{tabular}




\begin{tabular}{|c|c|c|c|}
\hline 174 & Fulful & Biber & Capsicum sp. L. \\
\hline 175 & Finduk & Fındık & Corilus maxsima \\
\hline \multicolumn{4}{|c|}{ KAF BABI } \\
\hline 176 & Kabak & Kabak & Cucurbita sp. \\
\hline 177 & Katır kuyruğu & Katırkuyruğu, atkuyruğu & Anaygiris foetida \\
\hline 178 & Kadun tuzlugı & Dikenüzümü, kadıntuzluğu & Berberis crataegina \\
\hline 179 & Karpuz & Karpuz & Citrillus lanatus \\
\hline 180 & Kurut & Kurutulmuş çökelek & \\
\hline 181 & Koruk & Koruk & \\
\hline 182 & Kuru üzüm & Kuru üzüm & \\
\hline 183 & Kuzgun otı & Kuzgu otu & Driopteris filix-mas \\
\hline 184 & Kızıl iğde & Kırmızı iğde & Elaeagnus multiflora $L$. \\
\hline 185 & Kasnı & Kadıağcı, şeytanboku & Ferula assa-foetida \\
\hline 186 & Katran & Katran & \\
\hline 187 & Kamış & Kamış, kargı & Arundo donax \\
\hline 188 & Kantariyun & Kantaron & Hypericum perforatum \\
\hline 189 & Kunduş taşağı & Çakşır otu & Ferula elaeochytris $L$. \\
\hline 190 & Koz & Ceviz & Juglans regia $L$. \\
\hline 191 & Kanbil & Güveyfeneri, kanbil otu & Physalis alkengi \\
\hline 192 & Kavak & Kavak & Populus alba \\
\hline 193 & Kavun & Kavun & Cucumis melo \\
\hline \multicolumn{4}{|c|}{ KEF BABI } \\
\hline 194 & Kasni & Hindiba, yaban marulu & Cichorium endiva \\
\hline 195 & Kebabe & Kebabe, kuyruklu biber & Piper cubeba \\
\hline 196 & Kebere & Kapari, kebere & Capparis spinosa \\
\hline 197 & Kepek & Kepek & \\
\hline 198 & Keraviya & Karaman kimyonu & Carum carvi $L$. \\
\hline 199 & Kesira & Kitre, geven dikeni & Astragalus sp. L. \\
\hline 200 & Küjen & Kızılcık ağacı & Cornus mas $L$. \\
\hline 201 & Kerefs & Kereviz & Apium graveolens \\
\hline 202 & Kerdeme & Kerdeme otu, su teresi & Lepidium sativum \\
\hline 203 & Kestene & Kestane & Castanea sativa $L$. \\
\hline 204 & Kişnic & Kişniş & Coriandrum sativum \\
\hline 205 & Keşur & Yaban havucu & Scorzonera mollis \\
\hline 206 & Gil-i ermeni & Ermeni kili & \\
\hline 207 & Gil-i bemuhre & Tıbbi ki, mühürlü balçık & \\
\hline 208 & Gül & Gül & Rosa sp. L. \\
\hline 209 & Gülguz & Kulkas otu & Colocasia esculenta \\
\hline 210 & Kelem & Lahana & Brassica oleracea \\
\hline 211 & Kimnun & Kimyon & Cuminum cyminum \\
\hline 212 & Gendena & Pırasa & Allium ampeloprasum \\
\hline 213 & Kene tohmı & Keneotu, bidencir, hintyağı & Ricinus communis \\
\hline 214 & Kündür & Ak günlük, buhur & Boswelia thurifera \\
\hline 215 & Kenevür & Kenevir, kendir & Cannabis sativa $L$. \\
\hline 216 & Kaşım-ı beyebani & Baldıran, yılan otu, şevkeran & Conium maculatum L. \\
\hline 217 & Köknar & Köknar & Abies cilicica \\
\hline 218 & Kehruba & Kehribar & \\
\hline
\end{tabular}




\begin{tabular}{|c|c|c|c|}
\hline 219 & Güyegü otu & Güvey otu, keklik otu & Origanum vulgare \\
\hline 220 & Kündus & Çöven otu & Gypsophia struthium L. \\
\hline 221 & Kübbad & Bir tür limon & \\
\hline \multicolumn{4}{|c|}{ MiM BABI } \\
\hline 222 & Marul & Marul & Lactuca sativa $L$. \\
\hline 223 & Mazu & Mazı ağacı & Thuja sp. L. \\
\hline 224 & Mercan & Mercan ağacı & Erytrina crista galli \\
\hline 225 & Maş & Mürdümük & Lathyrus sativus \\
\hline 226 & Mahmude & Mahmudiye otu & Convolvulus scammonia \\
\hline 227 & Mercimek & Mercimek & Lens culinaris \\
\hline 228 & Müşk & Misk & \\
\hline 229 & Mum & Mum & \\
\hline 230 & Mersin & Mersin, murt & Myrtus communis \\
\hline \multicolumn{4}{|c|}{ NUN BABI } \\
\hline 231 & Narinc & Turunç & Citrus airentium amara \\
\hline 232 & Nar & Nar & Punica granatum $L$. \\
\hline 233 & Nebat & Nebat şekeri & \\
\hline 234 & Nohud & Nohut & Cicer airetinum L. \\
\hline 235 & Nişeste & Nişasta & \\
\hline 236 & Nuşadır & Nişadır, amonyum klorür & \\
\hline 237 & Na'na & Nane & Mentha piperita $L$. \\
\hline 238 & Neft & Neft yağı & \\
\hline 239 & Nilüfer & Nilüfer çiçeği & Nymphea sp. \\
\hline \multicolumn{4}{|c|}{ VAV BABI } \\
\hline 240 & Vesligun & Fesleğen & Ocimum basilicum \\
\hline 241 & Venbel otı & Boyacı dikeni, cehri & Rhamnus petiolaris \\
\hline \multicolumn{4}{|c|}{ HE BABI } \\
\hline 242 & Helyun & Kuşkonmaz & Asparagus officinalis \\
\hline 243 & Hindustan kozı & Hindistan cevizi & Cocos nucifera \\
\hline \multicolumn{4}{|c|}{ YE BABI } \\
\hline 244 & Yağ & Yağ & \\
\hline 245 & Yaliki eyraltü & Eğrelti otu & Driopteris filix-mas \\
\hline 246 & Arslan yağı & Arslan yağı & \\
\hline 247 & Eşek yağı & Eşek yağı & \\
\hline 248 & Balık yağı & Balık yağı & \\
\hline 249 & Dilkü yağı & Tilki yağı & \\
\hline 250 & Deve yağı & Deve yağı & \\
\hline 251 & Sığır yağı & Sığır yağı & \\
\hline 252 & Tonuz yağı & Domuz yağı & \\
\hline 253 & Kaz ve ördek yağı & Kaz ve ördek yağı & \\
\hline 254 & Yaban hıyarı & Eşek hıyarı, acı dölek & Ecballium elaterium \\
\hline 255 & Yonca & Yonca & Medicago sativa \\
\hline 254 & Yumurda & Yumurta & \\
\hline 257 & Yund dişi & İtboğan, acı çiğdem & Colchicum autumnale \\
\hline 258 & Yantak & Yantak dikeni, demirdikeni & Ononis spinosa \\
\hline 259 & Yosun & Yosun & \\
\hline 260 & Yoğurt & Yoğurt & \\
\hline
\end{tabular}


Edviye-i Müfrede'nin ilk kısmının sonunda yer alan farklı endikasyonlar için hangi drogların kullanılacağı hakkındaki bilgiler Tablo 2'de özetlenmiştir.

Tablo 2. Hastalıklara veya Şikayetlere Karşı ya da Belirli Etkiler İçin Kullanılan Droglar Listesi.

\begin{tabular}{|c|c|}
\hline $\begin{array}{l}\text { Sağlık Sorunu ya da } \\
\text { İstenen Etki }\end{array}$ & Kullanılan Droglar \\
\hline Baş ağrısı & $\begin{array}{l}\text { Oğlan aşı, acıbadem yağı, anason, papatya, menekşe, sabırlık, sandal, oğulotu, } \\
\text { katranköpüğü mantarı, kabak yağı, koruk, kişniş, marul tohumu, nilüfer }\end{array}$ \\
\hline Soğuktan olan baş ağrısı & Katran, acur, kırmızı gül, çakşır, mahmudiye otu \\
\hline Kulak ağrısı & $\begin{array}{l}\text { Acıbadem yağı, turp yağı, çinkolu bileşik, soğan, şeker pancarı, sirke, buhar, } \\
\text { sumak, fındık yağı, katran, kenevir tohumu yağı, mazı, tilki yağı }\end{array}$ \\
\hline Şakak ağrısı & $\begin{array}{l}\text { Sarıyonca, papatya tohumu, küçük hindistan cevizi, hatmi, acur, amber çiçeği, } \\
\text { safran, nilüfer }\end{array}$ \\
\hline Göz ağrısı & Çinkolu bileşik, sirke, sumak, gülab \\
\hline Kulak dibinde olan şişler & Yabani rezene \\
\hline Burun kanaması & $\begin{array}{l}\text { Isırgan dikeni, yabani fesleğen, tavuk beyni, kişniş, pırasa, kimyon, güvercin kanı } \\
\text { ve yumurtası, kırmızı demir sülfat }\end{array}$ \\
\hline Ağız ağrısı & $\begin{array}{l}\text { Ilgın meyvesi, böğürtlen, topalak, sinir otu yaprağı, sığırdili, yalancı safran, } \\
\text { kebabe, kişniş, Ermeni kili, mazı }\end{array}$ \\
\hline Ağız kokusu & $\begin{array}{l}\text { Ilgın yemişi, tarhun otu, topalak, lüle taşı, zerdali, oğulotu, anber, kereviz, kişniş, } \\
\text { küçük hindistan ceviz }\end{array}$ \\
\hline Diş ağrısı & $\begin{array}{l}\text { Ebegümeci, ılgın yemişi, at sütü, kadife çiçeği, böğürtlen yaprağı, çınar kabuğu, } \\
\text { sirke, sarımsak, sarı boya otu, kapari, nohut suyu }\end{array}$ \\
\hline Boğaz ağrısı & $\begin{array}{l}\text { İt üzümü suyu, incir suyu, badem yağı, tarhun otu tohumu, dut suyu, acur, } \\
\text { kişniş, keklik otu, mercimek, amonyum klorür }\end{array}$ \\
\hline Boğazdan kan gelmesi & Yılan bıçağı, sabırlık, mum, mercimek, mersin \\
\hline Öksürük & $\begin{array}{l}\text { Ebegümeci, at sütü, ıspanak, çakşır otu, badem yağı, burçak, menekşe, turp, } \\
\text { haşhaş, erişte, şırlağan otu, sığırdili, kabak, katran, kavak yemişi, lahana, kitre, } \\
\text { marul, mürdümük, mülühıya, nişasta, neft yağı }\end{array}$ \\
\hline Grip & Çörek otu, tarçın, ketttan tütünü, sarımsak, marul, nişasta \\
\hline Kalp çarpıntısı & $\begin{array}{l}\text { Ak sandal, ağaç kavunu, karaman kimyonu, sığırdili, oğul otu, anber, kadı ağacı, } \\
\text { öd ağacı, lahana, kehribar, misk, nar }\end{array}$ \\
\hline Akciğer zarı iltihabı & Isırgan tohumu, badem yağı, menekşe, hatmi \\
\hline Dalak ağrısı & $\begin{array}{l}\text { Ebegümeci, it boncuğu, acı badem yağı, üzerlik, eğir otu, çöven, anason, } \\
\text { semizotu, soğan, çiğdem, hardal, lüle taşı, safran, söğüt, süsen, katranköpüğü } \\
\text { mantarı, biber, katırkuyruğu, kapari, boyacı dikeni, yaban hıyarı }\end{array}$ \\
\hline Felç ve yüz felci & $\begin{array}{l}\text { Bağboğan, bespaye, çakırdikeni, şeker pancarı, zencefil, sütleğen, ceviz yağı, } \\
\text { nohut suyu, neft yağı, kuşkonmaz, çiğdem }\end{array}$ \\
\hline Bağırsaklardaki gaz sancısı & Acı badem yağı, çakırdikeni, kına, yantak dikeni \\
\hline Siroz hastalığı & $\begin{array}{l}\text { İt üzümü yaprağı, ayva, tarçın, it kasarı, rezene, antimon, sütleğen, sirke, darı, } \\
\text { öd ağacı, katran, yaban havucu tohumu, kimyon, göynek }\end{array}$ \\
\hline Sarılık hastalığı & $\begin{array}{l}\text { Eşek turpu suyu, baldırı kara, çiğdem, acur, sarımsak, söğüt, sabırlı, sarı boya } \\
\text { otu, sığır eti, katırkuyruğu, katranköpüğü mantarı, güveyfeneri, limon, nane }\end{array}$ \\
\hline Alerjik cilt hastalıkları & Ebegümeci, kişniş, sandal, marul \\
\hline $\begin{array}{l}\text { Zararlı böcek ısırıkları ve yılan, çıyan, } \\
\text { akrep, zehirli böcek sokmaları }\end{array}$ & $\begin{array}{l}\text { Isırgan tohumu, elma, incir, hayıt yaprağı, yabani fesleğen, buğday, burçak, turp, } \\
\text { çörek otu, çiğdem, hıyar tohumu, tarçın, tuz, defne, rezene, zencefil, üçgül, } \\
\text { katranköpüğü mantarı, kadı ağacı, ceviz, kavak meyvesi, sarımsak, kiraz }\end{array}$ \\
\hline Zehirli maddeler & Ebegümeci, defne, keçi sütü, sarımsak, mahtum kili \\
\hline Nezle & Isırgan, kızıl iğde, Ermeni kili \\
\hline Uyuz ve kaşıntı & $\begin{array}{l}\text { Ilık su, bakam ağacı, menekşe, şahtere, lüle taşı, tuz, koyun sütü, oğul otu, } \\
\text { nohut yağı }\end{array}$ \\
\hline Kan gelmesi & $\begin{array}{l}\text { İğde, semizotu, tekesakalı, defne, sumak, kişniş, Ermeni kili, mahtum kili, güle } \\
\text { gan, kimyon, günlük, marul, nane, yosun }\end{array}$ \\
\hline Karındaki kurtlar & $\begin{array}{l}\text { Zakkum, karaman kimyonu, boraks, çiğdem, hardal, it kasarı, defne, sarımsak, } \\
\text { kuzgun otu, katran, güveyfeneri, ceviz, güvey otu, nane, neft yağı }\end{array}$ \\
\hline Karın geçirme & $\begin{array}{l}\text { Erik, incir, acur, durak otu, bozuk süt, sabırlık, katranköpüg̈ü mantarı, sütleğen, } \\
\text { kuru üzüm, nar }\end{array}$ \\
\hline Karını tutması & $\begin{array}{l}\text { İğde, alıç, ayva, peynir, bambu şekeri, sumak, yabani fesleğen, şahsiperum, darı, } \\
\text { kadıntuzluğu, koruk, kavak meyvesi, kadı ağacı, keten tohumu, kestane, Ermeni } \\
\text { kili, mahtum kili, kiraz, ladin, mazı, mersin, nişasta }\end{array}$ \\
\hline Karından sıcak humorların uzaklaşması & $\begin{array}{l}\text { Sinirli ot, arpa suyu, erik, iğde, ıspanak, semizotu, demirhindi, çörek otu, } \\
\text { çakırdikeni, hatmi, karpuz, menekşe }\end{array}$ \\
\hline Karından soğuk humorların uzaklaşması & Bağboğan, sarıyonca, papatya, bespaye, şahtere, Mekke balsamı, baldırı kara, \\
\hline
\end{tabular}




Basur hastalığı
Idrar tutulması
Doğum
Kasık ağrısı
Yanık
Sıcaktan olan şişlere yakı
Soğuk şişlere yakı
Susatan maddeler
Susuzluk gideren maddeler
İştah açan maddeler
Cinsel isteği arttıran maddeler

Cinsel isteği azaltan ve meniyi kurutan maddeler

İdrar ve adet söktüren maddeler

Gaz yapıcı

Gaz giderici

Sicak sitmalar

Soğuk sitmalar

Boğazdan kan gelmesi (iç organlardan)

Böbrek, mesane, idrar yolu taşı

Domuz çıbanı

Bel ağrısı

Kusmayı kesenler

Nezle ve diş ağrısı

Dizanteri

Derinin oyulması şeklinde görülen cilt hastalığı

\section{acur, mahmudiye otu}

it boncuğu, pırasa, durak otu

Badem yă̆ı, kimyon

İt boncuğu, börülce suyu, çemen otu, papatya suyu, ladin buharı

ìt boncuğu, güveyfeneri, su teresi tohumu

it boncuğu, eşek yağı

It üzümü, afyon, menekşe, bambu şekeri, hatmi, sandal, darı, kişniş, Ermeni kili, nilüfer, yosun

Papatya, sütleğen, çemen otu, çakırdikeni tohumu, çınar yaprağı, kına, tuz, demir sülfat, susam, Şam sakızı, ceviz, kepek, keten tohumu, günlük, boyacı dikeni

Üzüm, peynir, tarhun otu, susam, fesleğen, kavun

Arpa suyu, ayva, bambu şekeri, erik, demirhindi, hıyar, zerdali, şarap, sirke, sumak, şeftali, acur, kabak, kadıntuzluğu, güveyfeneri, marul, turunç, nar

Elma, hamama girmek, patlıcan, topalak, it kaşarı, zeytin, şarap, sirke, sumak, şeftali, sabırlık, limon, marul, turunç, yantak dikeni

Anason, bespase, baldırıkara, bal, çemen otu, hardal, hurma, haşhaş, baş biberi, demirdikeni, it kasarı, safran, zencefil, zeytin, şarap, sarımsak, soğan tohumu, sakız, susam, şeftali, yabani havuç, şalgam ve tohumu, fıstık, fındık, kadı ağacı, kunduz taşağı, ceviz, kavun tohumu, kiraz, güvey otu, nar, nohut, nane, kuşkonmaz, çiğdem, yonca tohumu

Semizotu, çok şarap içmek, kişniş, marul, hayıt

Arpa suyu, eğir otu, ayva, Mekke balsamı, dut, soğan, hatmi, hıyar, durak otu, demir dikeni, rezene, safran, at sütü, şarap, sarımsak, su teresi, yabani havuç, şalgam, darı, fındık, biber, kamış, kavun, kavak yemişi, kapari, kereviz, tere, lahana, kulkas otu, pırasa, nohut suyu, ladin boyacı dikeni, Yahudi taşı

Buğday, incir, börülce, dut, fındık, kadıntuzluğu, kestane, marul, neft yağı

Eğir otu, anason, acı badem, bespase, bespaye, karaman kimyonu, boraks, çemen otu, küçük hindistan cevizi, tarhun otu, baş biberi, durak otu, zencefil, sarımsak, sığırkuyruğu, oğul otu, anber, çakşır otu, koyun sütü, kepek suyu, yantak dikeni, çiğdem, yonca tohumu

Arpa suyu, acur (hıyarşenber), hıyar, semizotu, zerdali, sinirli ot, şeftali, acur (şınhıyar), sandal, kabak, karpuz, kadıntuzluğu, kadı otu, kişniş, Ermeni kili

Tarçın, kadı otu, çakşır otu

Mum, mercimek, mersin, yengeç

Papatya, baldırıkara, peynir, soğan kökü, topalak, defne meyvesi, su teresi, sedef otu, kebabe, kişniş, gül, limon, mürdümük, marul, civciv çıkmış yumurta Baldırıkara, hatmi, hardal, lüle taşı, zift, sinirli ot kökü, sedef otu, biber, kapari, kene ağacı, mercimek

Zakkum

Demir hindi, yaban havucu suyu, gül şurubu , elma suyu, güllü-ballı macun, sakız, Ermeni kili

Isırgan, ılgın, hıyar yaprağı, acur, zencefil, çörek otu

İğde, badem, darı, günlük, mercimek

Söğüt kökü, ısırgan tohumu

\section{Sonuç}

XIV. yüzyıl hekimi İshak bin Murad Grek-Roma uygarlığından İslam uygarlığına; Yunanca'dan Arapça'ya geçerek gelişimini sürdüren klasik tıp anlayışının görece geç döneminin bir temsilcisidir. Meslek yaşamı, bu anlayışın etkisini ve nüfuzunu sürdürdüğü ancak yorgunluk belirtileri vermeye başlamış bulunduğu bir aşamaya denk gelmiştir. Bu saptamalar bağlamında yaşamı ve kişiliği hakkında günümüz ulaşmış fazla bilgi bulunmayan yazar hakkında spekülatif bir değerlendirme yaparak onun mevcut bilgi birikimini arttırmayageliştirmeye yönelik bir motivasyon içinde olmadığını, aksine söz konusu birikimden yaptığı sınırlı bir seçkiyi ana dilinde yazmaya yöneldiğini söylemek olanaklıdır. Böylelikle meslektaşlarına gündelik uygulamalarda destek alabilecekleri bir el kitabı oluşturmak istemiş ve bunu da gerçekleştirmiş; eserinden görece uzun süre bu şekilde yararlanılmıştır. 
Edviye-i Müfrede ön plana çıkarak yazarının gölgede kalmasına yol açmış güçlü bir eserdir. O kuşaklar boyu ilgi çekmeyi sürdürerek günümüze ulaşmayı başarmış, İshak bin Murad ise geçmişin sisleri arasında ancak silueti seçilen bir figür olarak kalmıştır. Anadolu topraklarında kaleme alınmış olan bu kitap özel olarak bitkilerle tedavinin, genel olarak ana enstrümanı bitkilerle tedavi olan bir tıp anlayışının sakin-yorgun sona eriş dönemini temsil etmektedir. Uzun süre tıp uygulamalarına katkı destek sağlamış olan bu eser, günümüzde de bir şekilde işlevsel olabilmekte; tıbbın geçmişini anlamamızı-yorumlamamızı sağlayan bir kaynak olarak devreye girebilmektedir.

\section{Bilgi}

Bu makale yazarı Özgür Kıran, danışmanı Selim Kadıoğlu olan "De Materia Medica ve Edviye-i Müfrede Işığında Anadolu'da Bitkilerle Tedavi" başlıklı doktora tezinin Türkçe yazıımış ilk basit ilaçlar kitabı olan Edviye-i Müfrede ve onu kaleme alan İshak bin Murad ile ilgili bölümüne dayanmaktadır.

Yazarlar arasında herhangi bir çıkar çatışması bulunmamaktadır.

\section{Araştırmacı Katkı Oranı Beyanı}

Özgür Kıran: Fikir, tasarım, denetleme, veri toplama ve işleme, analiz ve yorum, kaynak taraması, makale yazımı, eleştirel inceleme, kaynak ve fon sağlama, malzemelerin sorumluluğu.

Selim Kadıoğlu: Fikir, tasarım, denetleme, veri toplama ve işleme, analiz ve yorum, kaynak taraması, makale yazımı, eleştirel inceleme, kaynak ve fon sağlama, malzemelerin sorumluluğu.

\section{Kaynaklar}

1. Kıran Ö. De Materia Medica ve Edviye-i Müfrede Işığında Anadolu'da Bitkilerle Tedavi. Danışman Kadıoğlu S. Adana: Çukurova Üniversitesi Sağlık Bilimleri Enstitüsü Tıp Tarihi ve Etik Anabilim Dalı Doktora Tezi; 2017.

2. İshak Bin Murad. Edviye-i Müfrede. Editörler Canpolat M, Önler Z. Ankara: Türk Dil Kurumu Yayınları; 2007.

3. Erdağı Doğuer B. Hekim Bereket Tuhfe-i Mübarizi: Metin-Sözlük. Ankara: Türk Dil Kurumu Yayınları; 2013.

4. Önler Z. Celalüddin Hızır (Hacı Paşa): Müntahab’ı Şifa. Ankara: Türk Dil Kurumu Yayınları; 1990.

5. Tercüme-i Müfredat-ı İbn Baytar. İstanbul: Sağlık Bilimleri Üniversitesi Yayınları; 2017.

6. Adıvar A. Osmanlı Türklerinde Illim. İstanbul: Remzi Kitabevi; 1939.

7. Canpolat M. XIV. Yüzyılda Yazılmış Değerli Bir Tıp Eseri: Edviye-i Müfrede. Türkoloji Dergisi 1973;5(1):21-47.

8. Uzel İ. Anadolu Tıp Tarihine Giriş. İstanbul: Türk Eskiçağ Bilimleri Enstitüsü Yayınları; 2008.

9. Baylav N. Eczacılık Tarihi. İstanbul: Yörük Matbaası; 1968.

10. Şehsuvaroğlu BN. Eczacılık Tarihi Dersleri. İstanbul: İstanbul Üniversitesi Yayınları; 1970.

11. Baytop T. Türkiye'de Bitkiler ile Tedavi: Geçmişte ve Bugün. İkinci Baskı. İstanbul: Nobel Tıp Kitabevleri; 1984.

12. Uludağ OŞ. Beş Buçuk Asırlık Türk Tababeti Tarihi. Editör Uzel İ. Ankara: Kültür Bakanlığı Yayınları; 1991.

13. Uzluk FN. Genel Tıp Tarihi. Ankara: Ankara Üniversitesi Yayınları; 1958.

14. Bayat AH. Tıp Tarihi. İzmir: Sade Matbaa; 2003.

15. Murad S. Terceme-i Akrabadin'de Terkipler ve Adlandırmaları. Osmanlı Bilimi Araştırmaları 2011;12(2):81-94.

16. Demirhan Erdemir A. Geredeli İshak: XIV. Yüzyılda Yaşayan Bir Osmanlı Hekimi. Türkiye Diyanet Vakfı İslam Ansiklopedisi 14. Cilt İçinde. İstanbul: Türkiye Diyanet Vakfı İslam Araştırmaları Merkezi Yayını; 1996:30-31.

17. Önler Z. İshak bin Murad ve "Edviye-i Müfrede" Adlı Eseri. Türk Tarihinde İz Bırakan Bolulular Çalıştayı; 21-22 Ağustos 2015; Bolu-Türkiye. Erişim: (https://www.academia.edu/25812849/\%C4\%BOSHAK_B\%C4\%BON_MURAD_VE_EDV\%C4\%BOYE\%C4\%BO_M\%C3\%9CFREDE_ADLI_ESER\%C4\%B0). Erişim Tarihi: 31.08.2021.

18. Ağırakça A. Osmanlı Tıbbının Kaynakları. Editörler Yılmaz N, Yılmaz C. Osmanlılarda Sağlık I: Makaleler, Araştırmalar, Arşiv Belgeleri. İstanbul: Biofarma Yayınları; 2006:133-163.

19. İbn-i Sina. El-Kanun Fi't-tıbb İkinci Kitap. Çeviren Kahya E. Ankara: Atatürk Kültür Merkezi Başkanlığı Yayınları; 2003.

20. Argunşah M. Edviye-i Müfrede'nin Neşri Üzerine Düşünceler. Türk Kültürü 2009;185-196

21. Baytop T. Türkçe Bitki Adları Sözlüğü. Ankara: Türk Dil Kurumu Yayınları; 1994.

22. Tuzlacı E. Türkiye Bitkileri Sözlüğü: Bitki Adlarının Özel Açıklamaları. İstanbul: Alfa Yayınları; 2006.

23. Tuzlacı E. Şifa Niyetine Türkiye’nin Bitkisel Halk İlaçları. İstanbul: Alfa Yayınları; 2006.

24. Baytop T. Türkiye'nin Tıbbi ve Zehirli Bitkileri. İstanbul: İstanbul Üniversitesi Yayınları; 1966.

25. Önler Z. XIV-XV. Yüzyıl Tıp Metinlerinde Türkçe Bitki Adları. Kebikeç Dergisi 2004;(18):273-301.

26. Önler Z. XIV. ve XV. Yüzyıl Anadolu Türkçesi Botanik Terimleri. Journal of Turkish Studies (Fahir İz Armağanı I) 1990; 14: $357-392$. 